\title{
Optimized PID Controller for a Self-lift Positive Output Luo-Converter
}

\author{
Muhammed A. Ibrahim ${ }^{1}$, Salam Ibrahim Khather ${ }^{2}$ \\ \{muhammed.ibrahim@uoninevah.edu.iq, salam.khather@uoninevah.edu.iq\} \\ Systems and Control Engineering Department, College of Electronics Engineering \\ Ninevah University, Mosul, Iraq 1\&2
}

\begin{abstract}
Voltage lift method opens a suitable way to enhance characteristics of DC-DC converters Self-lift can be defined as a typical approach extensively utilized in developing a DC-DC converter for amplifying output voltage. The use of the self-lift approach in the DC-DC conversion technologies result in designing the positive output Luo power converters with a high voltage transfer gains in the mathematical progression, such approach open the way to securely increasing voltage transfer gain that is related to the DC/DC converters as well as enhancing specifications regarding DC-DC converters. These converters could be utilized in the industrial applications as well as the computer peripheral equipment, particularly with regard to the high-output-voltage projects. Self-lift Positive Output Luo Converter in addition to the PID controller, therefore designed in the presented work, has appropriate output voltage regulations, also there aren't undershoots or overshoots and has been very effective. Detailed and full analysis regarding circuit in addition to discrete in addition to optimized PID controllers with the $\mathrm{ABC}$ algorithms was conducted. Furthermore, extensive simulations have been conducted and the results have been specified. PID controller platform has been proved with the use of MATLAB/Simulink model.
\end{abstract}

Keywords: DC-DC Luo converter, Artificial Bee Colony (ABC), Self-lift positive output Luo Converter, PID controller.

\section{INTRODUCTION}

In the past decades, the DC-DC converters have been significantly utilized in power electronics applications. Recently, the research development, as well as manufacture, was extensively applied. DC-DC converters are having some features when compared to linear power supplies. Also, they are comparable in their size, yet it has high efficiency as well as high power density[1].

Being considered as major selection regarding converters change the major converters are developed and newly advanced self-lift positive output Luo converter. Luo converters are showing a lot of features like a simple startup, extremely low inrush current, high voltage conversion ratio, small size, high power density, micropower conversion, as well as high output voltage with the smooth ripples[2]. Along with such benefits, the self-lift approach has utilized the Luo converters that result in designing converters with compact and high-efficient DC-DC converters, as well as permitting output voltage increase in the arithmetic progression one stage at a time[1,2,3]. A lot of control approaches were examined with regard to dc-dc converters and major robust tuning method has been optimized PID controller that is providing excellent dynamic performances regardless of supply as well as load changes [1]. 
The most comprehensive analysis indicates as well as the simulations regarding various topologies related to Luo converter with voltage lift approach. It was specified that this approach exceeds the effect regarding parasitic elements in the traditional dc-dc converters as well as a massive extent for increasing output voltage levels [2]. Six distinctive DC-DC converters specified that have been prepared as well as resolved through the self-lift approach. Also, the study indicated that DC-DC converters have been provided through such an approach have been distinctive from conventional methods as well as displaying more effective performance. Also, the study suggested their applications in industries as well as consumer engineering products [3]. The details specified of novel approaches to design and tune PID Controllers that are including PID software packages, patentability PID tuning principles as well as the commercial hardware modules [4].

The full design and calculations with respect to the voltage lift approach indicated a lot of developed Luo converters. It was verified that such an approach decreases voltage-transfer gains concerning the discontinuous and continuous mode of operation [5].

The series SEPIC Converter with the voltage lift approach was specified. The study indicated that the SEPIC converter consequently developed with the use of such an approach has more advantages in many parts including high voltage transfer gain, easy circuit designs with no transformers or cascade connections [6]. Set up an automatic tuning key approach about the proportioned send-on-delta event- constructed PI controller. It might be indicated that the developed approach is providing proof regarding the high performance to measurement noise as well as initial PI tuning [7].

The tuning approach specified based on Ziegler- Nichols technique has been suggested, special structure regarding the proportional resonant controller. Also, it was indicated that the tuning approach offered suitable results as well as the performance with regard to fairly all the conditions, for reference frequencies below the final frequency [8].

The self-lift approach stated combining with the maximum power point tracking (MPPT) controllers as well as showing indications regarding effective tracking that is related to the required output voltage [9]. An efficient method introduced to build a representation for DCDC buck-boost converters by MATLAB / software. Tuning progression of PID controllers created on identification circuit data used to obtain PID parameters to overcome the complexity and nonlinearity of the load voltage control mode [10].

It is obvious that a robust controller is needed to verify the performance characteristic of the control system in the power electronics circuit. The control goal is to achieve a closely constant output load voltage of a self lift positive output Luo-converter. However, the output voltage of non-minimum phase systems is complicated in the design process. The major goal of this study is to develop and examine the ABC-PID controller for the proposed converter to increase the robustness of the system.

\section{MATHEMATICAL MODELING AND CIRCUIT ANALYSIS}

Each self lift converters are originated from expanded converters for example Luo converters[11]. A self-lift positive output Luo-Converter and its circuits equivalent throughout the switch-on and switch off cycles are shown in Figure 1 [11]. It is considered that the converter works in continuous conduction mode. The converter involves two inductors Lo and L, three capacitors Co, C1, and C, two diodes D1, D, and a semiconductor switch S. [12]. 


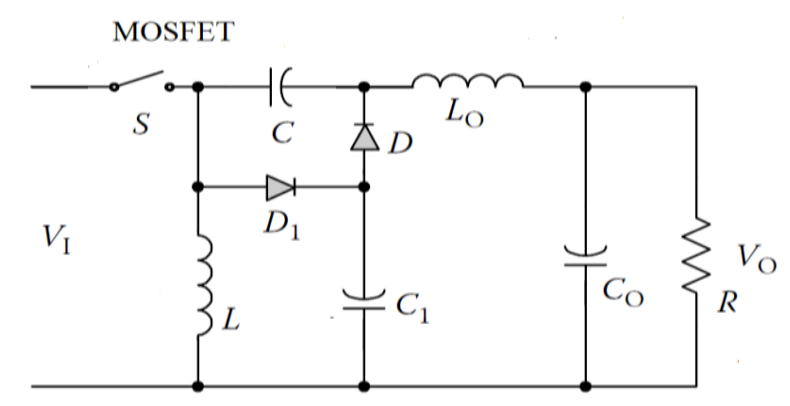

(a)
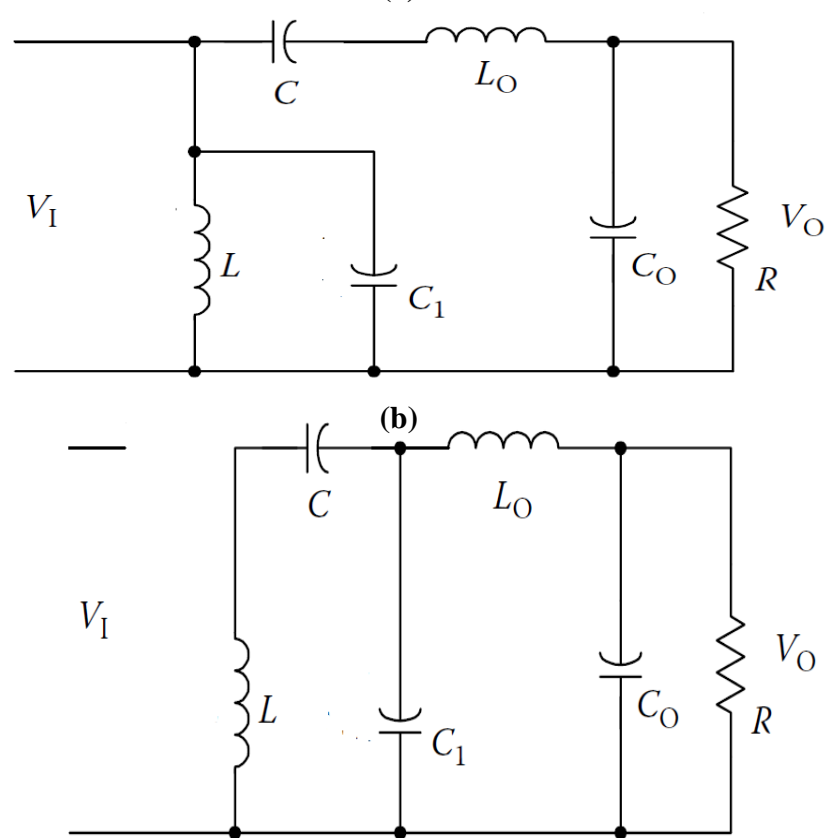

(c)

Fig. 1. (a) Self-lift positive output Luo-Converter circuit equivalent

(b) Mode 1 operation(switch-on)

(c) Mode 2 operation (switch off).

V1, and Vo denote the input voltage and output load voltage. Along with the self-lift circuit regarding P/O Luo-converters. Also, it has been obtained from the elementary circuit regarding P/O Luo-converters. Throughout the period of the switch-on, S, as well as D1, have been switched on, also D has been switched off. Throughout the period of the switch-off, D can be on, also $S$ as well as D1 can be off [11].

With regard to the steady-state, the average regarding the inductor voltage values over the period has been equal to 0 . Therefore,

$$
\mathrm{VC}=\mathrm{VCO}=\mathrm{VO} \text {. }
$$

Throughout the switch-on period, the voltage over the capacitor $\mathrm{C} 1$ has been equal to the voltage of the source. Assuming that $\mathrm{C}$, as well as $\mathrm{C} 1$, have been large, 
$\mathrm{VC} 1=\mathrm{VI}$.

Inductor current iL increase in the period of the switch-on as well as a decrease in the switchoff period. Furthermore, the equivalent voltages across the L have been VI in addition to (VC-VC1). Thus,

Therefore,

$$
\mathrm{kTVI}=(1-\mathrm{k}) \mathrm{T}(\mathrm{VC}-\mathrm{VC} 1) .
$$

$$
\mathrm{VO}=(1 /(1-\mathrm{k})) \mathrm{VI}
$$

Voltage transfer gain in continuous conduction mode (CCM) has been as develops:

$$
M=\frac{V_{O}}{V_{I}}=\frac{1}{1-k}
$$

Due to the fact that all components have been ideal, power loss related to circuit elements has been ignored. Thus, output power $P_{O}$ has been equal to input power $P_{I N}$

Therefore,

$$
V_{O} I_{O}=V_{I} I_{I}
$$

$$
I_{I}=\frac{1}{1-k} I_{O}
$$

Capacitor $C_{O}$ acting as a low-pass filter, therefore $I_{L O}=I_{O}$. The charge related to the capacitor $\mathrm{C}$ increase throughout switch-on as well as decrease throughout switch-off:

$$
\begin{aligned}
& Q_{+}=I_{C-o n} k T=I_{O} k T \\
& Q_{-}=I_{C-o f f}(1-k) T=I_{L}(1-k) T .
\end{aligned}
$$

With regard to the switching period, $Q_{+}=Q_{-}$and $I_{L}=\frac{k}{1-k} I_{O}$. Throughout the switch-off period, $i_{D}=i_{L}+i_{L O}$.Thus,

$$
I_{D}=I_{L}+I_{L O}=\frac{1}{1-k} I_{O}
$$

The resulting are the characteristic equations of a self-lift positive output Luo-Converter [11].

Current variations:

$$
\zeta=\frac{k}{2 M^{2}} \frac{R}{F_{s} L_{e q}}
$$

In which $L_{e q}$ indicating

Voltage variations:

$$
L_{e q}=\frac{L L_{O}}{\left(L+L_{O}\right)}
$$

$$
\varepsilon=\frac{k}{8 M} \frac{1}{{ }_{F}^{2} L_{O} C_{O}}
$$

The parameters of the proposed self-lift positive output Luo converter are listed in table1.

Table 1. Converter circuit parameter

\begin{tabular}{lll}
\hline Parameter & Symbol & Value \\
\hline Input inductor & L & $1.5 * 10^{-5}$ \\
Output inductor & Lo & $1.5 * 10^{-5}$ \\
Capacitor & C & $2.1 * 10^{-5}$ \\
Capacitor & C1 & $2.5 * 10^{-5}$ \\
Capacitor & Co & $2.5 * 10^{-5}$ \\
\hline
\end{tabular}




\begin{tabular}{llc}
\hline Power output & Po & $100 \mathrm{~W}$ \\
Input voltage & V1 & $20 \mathrm{~V}$ \\
Switching frequency & Fs & $50 \mathrm{KHz}$ \\
Power switch & $\mathrm{S}$ & $M O S F E T$ \\
Resistor & $\mathrm{R}$ & $25 \Omega$ \\
\hline
\end{tabular}

\section{CONTROL APPROACH}

Control plays a central role in automation and complex industrial processes. The PID control is intended to confirm the requiring requested nominal operating point for self-lift positive output Luo converter. Consider PID controller law regarding form [13].

Where:

$$
u(t)=K_{p} * e(t)+K_{i} \int e(t)+K_{d} \frac{d e(t)}{d t}
$$

$\mathrm{u}(\mathrm{t})$; control signal output.

$\mathrm{e}(\mathrm{t})$; Error signal.

$\mathrm{k}_{\mathrm{p}}$; Proportional factor.

$\mathrm{k}_{\mathrm{i}}$; Integral factor.

$\mathrm{K}_{\mathrm{d}}$; Derivative factor.

Self-lift positive output Luo-Converter modeled using power electronics switch (MOSFETs) that cannot be linearized for linear PID controller design. PID controller has been a majorly benefited controller in a lot of the engineering control systems. Yet, adequately tuning the PID controller isn't simple even though it has at most 3 parameters. The difficulty especially coming from certain conflict requirements regarding the control system performance, also partly because of the complicated effect of PID parameters on the control performance. The important point to consider in the PID controller design for self-lift positive output Luo-Converter is how to calculate controller coefficients $(\mathrm{kp}, \mathrm{ki}, \mathrm{kd})$. In order to locate the optimal PID controller parameters. Artificial bee colony ABC is used to design PID controller coefficients in the proposed work. The arrangement of the PID controller with ABC algorithms is presented in Figure 2.

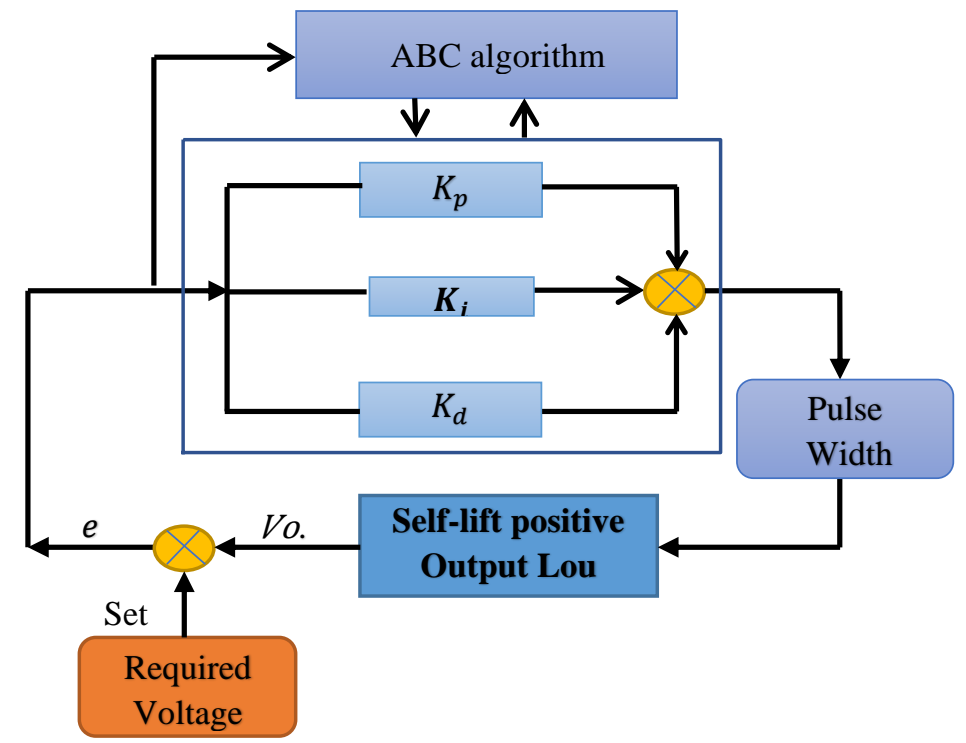


Fig. 2. The arrangement of the PID controller with $\mathrm{ABC}$ algorithms.

\section{PID CONTROLLER DESIGN BASED ON ARTIFICIAL BEE COLONY ALGORITHM}

The artificial bee colony (ABC) algorithm can be considered as one of the swarms established meta-heuristic algorithms which were developed to solve multimodal and multidimensional optimization problems, this algorithm is fairly new associated with regard to the swarm intelligence approaches. It has been suggested via Karaboga [14], this algorithm involves 3 bees' collections (employed bees, onlooker bees, scouts). Each collection has a special assignment in optimization development. The employed bees abuse the food resources and transmit the data around food resources back to the hive. They distribute such data with onlooker bees through boogying in elected boogie zone interior the hive. The nature of boogie is relational to the nectar gratified of food resource just abused by the boogying bee. The onlooker bees are remaining in the hive for the data and watching the boogie of the employed bees inside the hive, to choose a food resource. Therefore, suitable food resources invite supplementary onlooker bees evaluated to naughty ones. Whenever a food resource is used completely, all the employed bees related to it recklessness the food resource, and become a scout. Scout bees investigate for novel food resources. Employed and onlooker bees can be seen as an accomplishment of the work of manipulation, whereas scout bees can be seen as an accomplishment of the work of search [14][15].

For load voltage control of the self-lift positive output, Luo converter has been modeled in MATLAB/SIMULINK. The output load voltage regarding the converter is observed as the nectar amount. The duty cycle (D) of the self-lift positive output Luo-Converter is the decision variable that is characterized as a food resource position in the ABC algorithm [15]. The ABC algorithms are applied to search its globally optimal gains (kp, ki, kd) for the PID controller. The cost function of the Absolute time error method is given by the following [13][17][18]:

$$
\begin{aligned}
& I S E=\int_{0}^{t s i m} e^{2}(t) d t \\
& I A E=\int_{0}^{t s i m .}|e(t)| d t
\end{aligned}
$$

The optimization program is employed by employing a MATLAB m-file program and connected with the system model program in MATLAB/SIMULINK[19].

Flowchart of the intended ABC algorithm can be seen in Figure 3. 


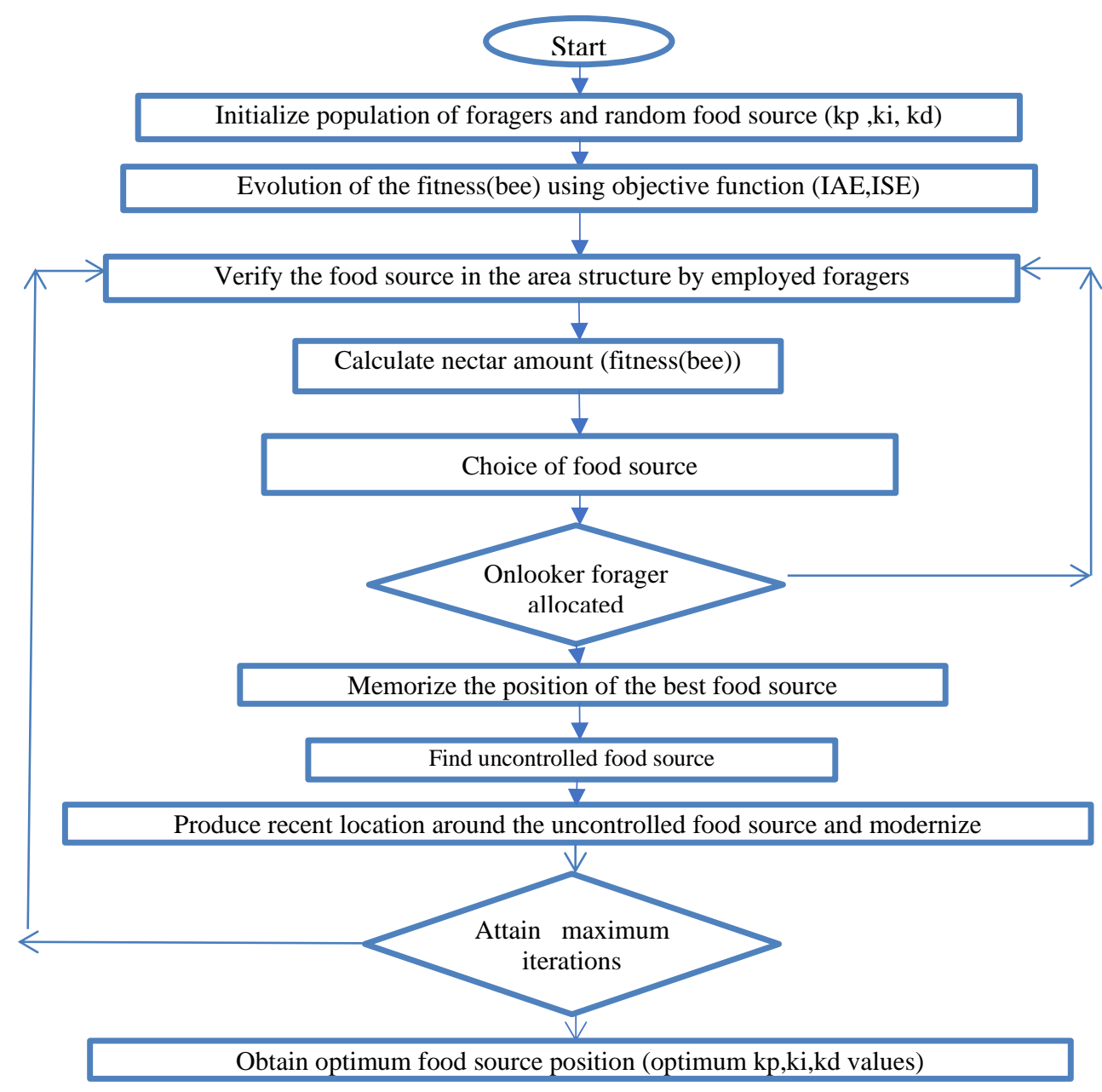

Fig. 3. The flowchart of ABC-PID control system

\section{SIMULATION AND RESULTS}

To prove the ability and robustness regarding the suggested controller design, the response of the self-lift positive output Luo-Converter Converter is tested under numerous kinds of operations. The representation that is related to the closed-loop control system of self-lift positive output Luo-Converter model in MATLAB software can be seen in Figure 4. 


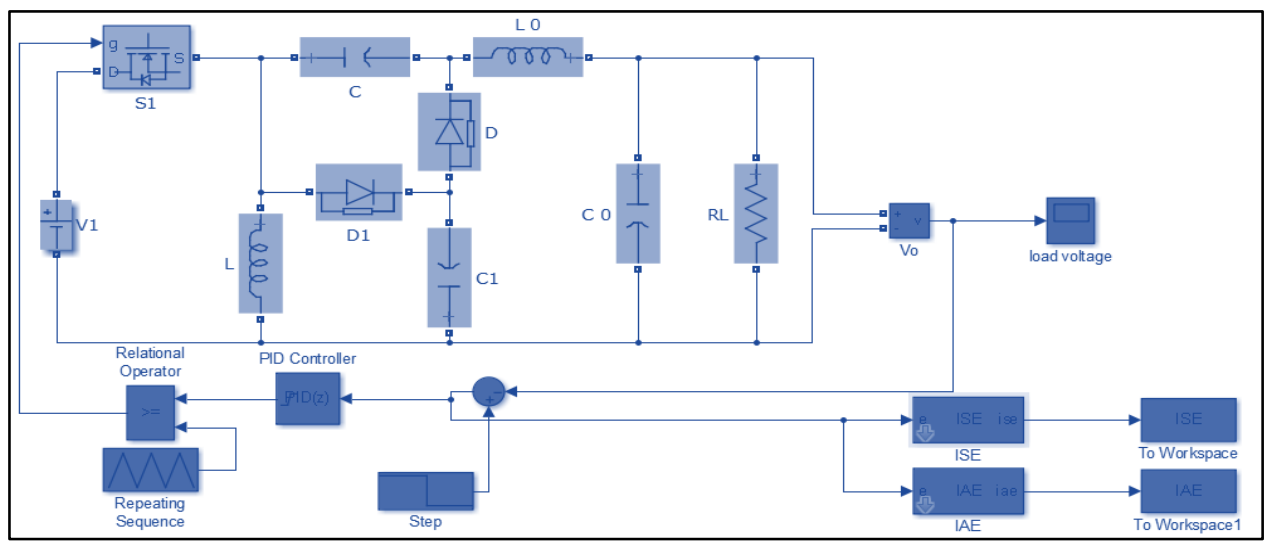

Fig. 4. self-lift positive output Luo-Converter with closed-loop controller simulation diagram.

\subsection{Start-up condition}

Figure 5. depicts the simulation waveforms related to output voltages of Luo converter with the closed-loop converter in the time domain and take into consideration the light and heavy condition of the reference output voltages as $(40 \mathrm{~V}, 60 \mathrm{~V}$ and $80 \mathrm{~V})$. There isn't overshoot in the transient response regarding all start-up conditions. From the simulation results of this condition, it might be indicated that output voltage has a quick rise time (4 msec) for $40 \mathrm{~V}$ (light condition). Also, the rise time of the output voltage response is closed to $(6 \mathrm{msec})$ without overshoot for $80 \mathrm{~V}$ (heavy condition).

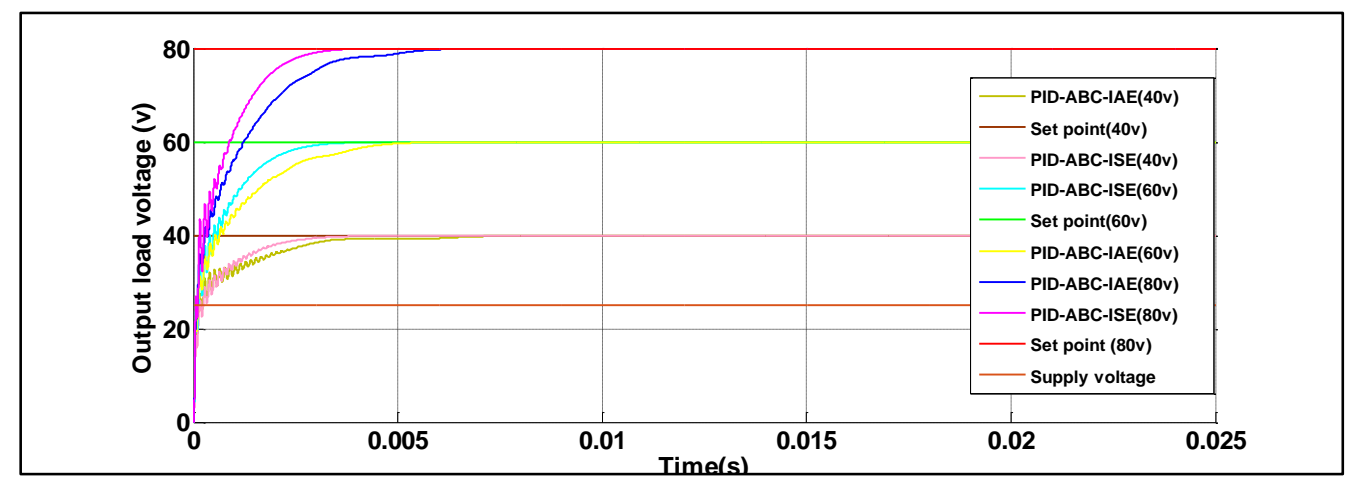

Fig. 5. output load voltage startup $(80 \mathrm{v}, 60 \mathrm{v}, 40 \mathrm{v})$, Start-up condition of the proposed system for load voltages $(80 \mathrm{v}, 60 \mathrm{v}, 40 \mathrm{v})$.

\subsection{Reference tracking condition}

The desired output voltage good tracks its reference signals under system uncertainties with an acceptable response as can be seen in Figure 6. 


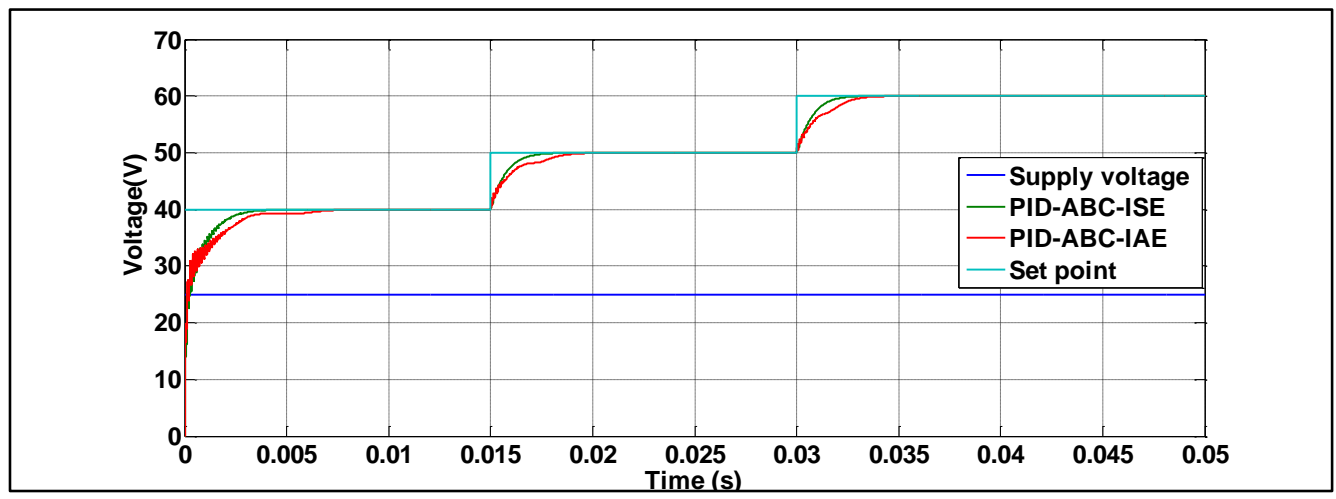

Fig. 6. output load voltage in reference tracking condition $(40 \mathrm{v}, 50 \mathrm{v}, 60 \mathrm{v})$ at $\mathrm{t}=0.015 \mathrm{~s}, \mathrm{t}=0.03 \mathrm{~s}$

\subsection{Supply disturbance condition}

To improve the influence of the controller, the converter response examined of disturbance of the sudden change in the supply voltage from $25 \mathrm{~V}$ to $28 \mathrm{~V}$ then $25 \mathrm{~V}$, while keeping the output voltage response at $40 \mathrm{~V}$ is shown in Figure 7.

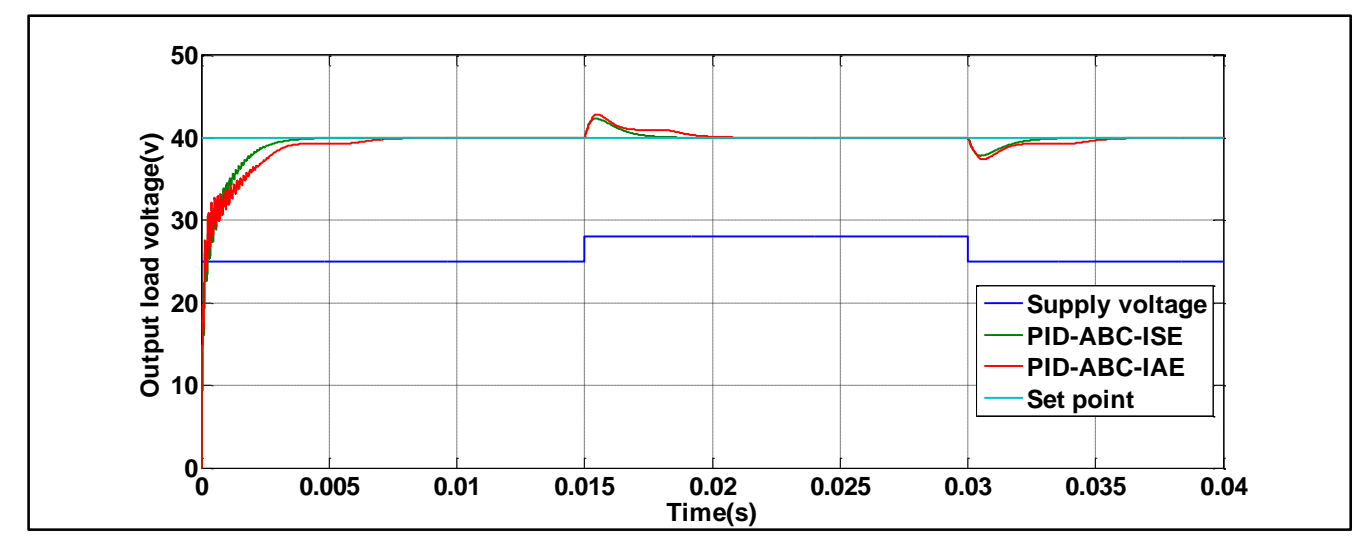

Fig. 7. Output load voltage in Supply disturbance condition $(25 \mathrm{v}, 28 \mathrm{v}, 25 \mathrm{v})$ at $\mathrm{t}=0.015 \mathrm{~s}$ and $\mathrm{t}=0.03 \mathrm{~s}$.

\subsection{Load disturbance condition:}

Figure 8. shown the load disturbance condition by the sudden change in the load from $25 \Omega$ to $20 \Omega$ then $25 \Omega$. It is clear that the converter response shown a small change in the rise time and settling time, also without overshoot. 


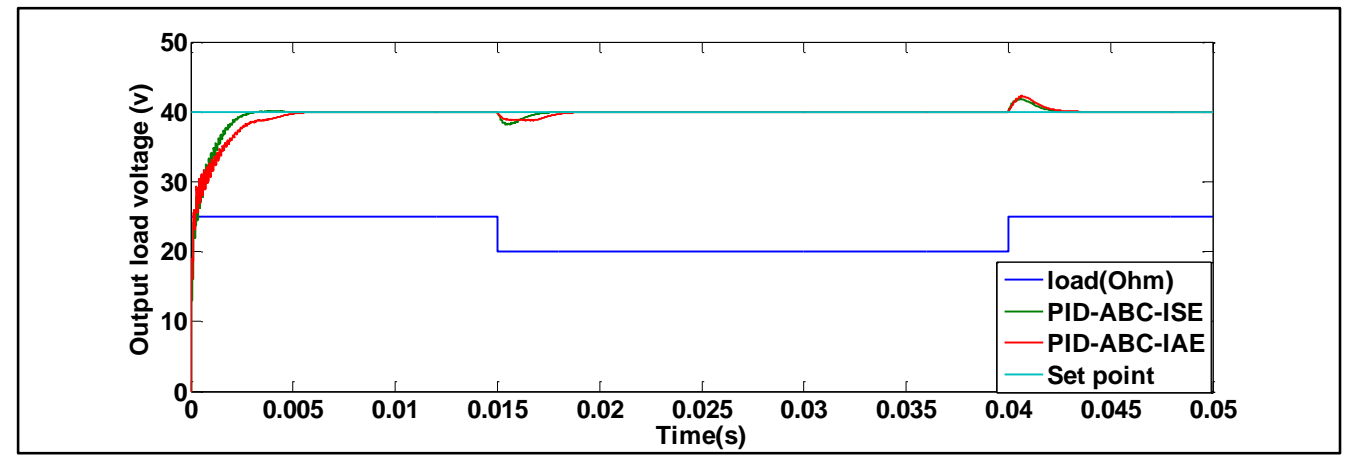

Fig. 8. output load voltage in Load disturbance condition $(25 \Omega, 20 \Omega, 25 \Omega)$ at $t=0.015 \mathrm{~s}$ and $\mathrm{t}=0.04 \mathrm{~s}$

\subsection{Time response characteristics:}

Table 2. showing the results related to the time response characteristic of the Luo converter with PID-ABC controller design with two types of cost function as PID-ABC-IAE and PIDABC-ISE. The results confirm that the controller gives a smooth response without overshoot and no steady-state error. Using the PID-ABC controller is observed by PID-ABC-IAE that the rise time 2.11 (msec) and settling time 6.5 ( $\mathrm{msec}$ ), but PID-ABC controller is observed by PIDABC-ISE that the rise time 1.3 (msec) and settling time 3.5 (msec). The performance index PIDABC-ISE has advantages like less settling time and fast rise time.

Table 2. Result of time characteristics

\begin{tabular}{lll}
\hline parameters & PID-ABC-IAE & PID-ABC-ISE \\
\hline Rise time(s) & 0.002112 & 0.0013223 \\
Settling time(s) & 0.006555 & 0.003537 \\
Overshoot (\%) & 0 & 0 \\
Steady state error & 0 & 0 \\
Closed loop stability & Stable & stable \\
\hline
\end{tabular}

The simulation results have been provided for verifying the performance and robustness of the optimized PID controller with regard to self-lift positive output Luo-converter. The controller in the system shown high robustness to the reference tracking condition and supply disturbance condition than load disturbance condition, furthermore the start-up condition.

\section{CONCLUSIONS}

The article effectively demonstrates the modeling and simulation of the self-lift positive output Luo-Converter as well as the implementations regarding the PID-ABC controller and tested under different conditions by MATLAB_SIMULINK.

The presented work showing that the settling time and rise time regarding the PID-ABC controller have been less in comparison to its analog matching part. It has been indicated that the converter with a PID controller designed on the basis of the ABC algorithm has been powerful, greater efficiency calms down fast with no steady-state. No more undershoots and overshoots, also the converter in addition to the controller has been qualified for tracking the needed references in spite of line as well as load changes. Therefore, it is suitable for several 
stable power supplier real-world industrial usages and it is essentially intended for power supply in special medical devices and military applications, especially for high voltage transfer gain requests particularly for high output voltage developments.

\section{REFERENCES}

[1] Kamat, Shruti Narayan, and R. Shenbagalakshmi. "Design and Analysis of Positive Output Self Lift Luo Converter." 2018 Fourth International Conference on Computing Communication Control and Automation (ICCUBEA). IEEE, 2018.

[2] Luo, Fang Lin. "Positive output Luo converters: voltage lift technique." IEE proceedingselectric power applications 146.4 (1999): 415-432.

[3] Luo, Fang Lin. "Six self-lift DC-DC converters, voltage lift technique." IEEE Transactions on Industrial Electronics 48.6 (2001): 1268-1272.

[4] Ang, Kiam Heong, Gregory Chong, and Yun Li. "PID control system analysis, design, and technology." IEEE transactions on control systems technology 13.4 (2005): 559-576.

[5] He, Y., and F. L. Luo. "Analysis of Luo converters with voltage-lift circuit." IEE ProceedingsElectric Power Applications 152.5 (2005): 1239-1252.

[6] Zhu, M. U., and F. L. Luo. "Series SEPIC implementing voltage-lift technique for DC-DC power conversion." IET Power Electronics 1.1 (2008): 109-121.

[7] Beschi, Manuel, et al. "An automatic tuning procedure for an event-based PI controller." 52nd IEEE Conference on Decision and Control. IEEE, 2013.

[8] Pereira, Luís Fernando Alves, and Alexandre Sanfelice Bazanella. "Tuning rules for proportional resonant controllers." IEEE Transactions on Control Systems Technology 23.5 (2015): 20102017.

[9] Amirtharaj, S., and L. Premalatha. "Design of an Efficient Positive Output Self-Lift and Negative Output Self-Lift Luo Converters using Drift Free Technique for Photovoltaic Applications." Energy Procedia 117 (2017): 651-657.

[10] Almaged, Mohammed, Salam Ibrahim Khather, and Abdulla I. Abdulla. "Design of a discrete PID controller based on identification data for a simscape buck boost converter model." International Journal of Power Electronics and Drive Systems 10.4 (2019): 1797.

[11] Luo, Fang Lin, and Hong Ye. Power electronics: advanced conversion technologies. CRC press, 2018.

[12] Goudarzian, Alireza, and Adel Khosravi. "Design, analysis, and implementation of an integral terminal reduced-order sliding mode controller for a self-lift positive output Luo converter via Filippov's technique considering the effects of parametric resistances." International Transactions on Electrical Energy Systems 29.4 (2019): e2776.

[13] S Dawood, Younis, Ali K Mahmood, and Muhammed A Ibrahim. "Comparison of PID, GA and Fuzzy Logic Controllers for Cruise Control System." International Journal of Computing and Digital Systems 7.05 (2018): 311-319.

[14] soufyane Benyoucef, Abou, et al. "Artificial bee colony based algorithm for maximum power point tracking (MPPT) for PV systems operating under partial shaded conditions." Applied Soft Computing 32 (2015): 38-48.

[15] Oshaba, A. S., E. S. Ali, and SM Abd Elazim. "PI controller design using ABC algorithm for MPPT of PV system supplying DC motor pump load." Neural Computing and Applications 28.2 (2017): 353-364.

[16] Sundareswaran, Kinattingal, et al. "Enhanced energy output from a PV system under partial shaded conditions through artificial bee colony." IEEE transactions on sustainable energy 6.1 (2014): 198-209.

[17] Muhammed A. Ibrahim, Ausama Kh. Mahmood and Nashwan Saleh Sultan, "Optimal PID controller of a brushless dc motor using genetic algorithm, "International Journal of Power Electronics and Drive Systems (IJPEDS), Vol 10, No 2: June 2019.

[18] Gao, Wei-feng, and San-yang Liu. "A modified artificial bee colony algorithm." Computers \& Operations Research 39.3 (2012): 687-697. 
[19] Oshaba, A. S., E. S. Ali, and SM Abd Elazim. "PI controller design using ABC algorithm for MPPT of PV system supplying DC motor pump load." Neural Computing and Applications 28.2 (2017): 353-364. 